\title{
PLANEJAMENTO, CONDUÇÃO E ANÁLISE DO MÉTODO DE AVALIAÇÃO DE UMA DISCIPLINA DO CURSO DE ENGENHARIA DE PRODUÇÃO FUNDAMENTADA NA APRENDIZAGEM BASEADA EM PROBLEMAS
}

\section{PLANNING, IMPLEMENTATION AND ANALYSIS OF AN ASSESSMENT METHOD OF AN INDUSTRIAL ENGINEERING COURSE GROUNDED ON PROBLEM BASED LEARNING}

\author{
Camila Pereira Pinto* E-mail: camilapereirapinto@yahoo.com.br \\ Anna Paula Galvão Scheidegger E-mail: anninha pgs@hotmail.com \\ Juliana Helena Daroz Gaudêncio* E-mail: ju gaudencio@hotmail.com \\ João Batista Turrioni` E-mail: joabatu@gmail.com \\ *Universidade Federal de Itajubá (UNIFEI), Itajubá, MG
}

\begin{abstract}
Resumo: Em um mercado altamente competitivo, as empresas necessitam de recursos humanos cada vez mais qualificados, em especial no que se refere à Engenharia. As Universidades desempenham, pois, um papel importante, ao formar os futuros profissionais do país. No entanto, nesta tarefa, as Instituições deparam-se com o desafio de atrair e trabalhar com jovens da Geração $Y$, que apresentam anseios não mais atendidos apenas pelos métodos tradicionais de ensino. $A$ Aprendizagem Baseada em Problemas (ABP) é uma abordagem que visa estudar e desenvolver alternativas de ensino que atendam às exigências das empresas, bem como o novo perfil de estudantes. Além disso, ensinar ativamente por si só não é uma tarefa simples e torna-se mais complexa quando é preciso avaliar o conhecimento adquirido através desse método. Deste modo, este trabalho busca apresentar o planejamento, a condução e o método de avaliação adotado em uma disciplina de Engenharia de Produção na Universidade Federal de Itajubá fundamentada na ABP. Para isso, adotou-se o método de pesquisa-ação, onde os autores participaram ativamente das etapas da disciplina, atuando como facilitadores no planejamento, implementação e monitoramento desta e do método de avaliação adotado. Como resultados, destacam-se os benefícios alcançados pelos envolvidos através do ensino ativo, bem como os pontos fortes e fracos do método. Além disso, propõem-se melhorias para futuras disciplinas.
\end{abstract}

Palavras-chave: Aprendizagem Baseada em Problemas. Projeto Semestral Europeu. Ensino Ativo. Ensino em Engenharia. Métodos de avaliação.

\begin{abstract}
In a highly competitive market, companies need increasingly skilled human resources, especially when it comes to engineering. Universities, therefore, play an important role in this scenario, while training future professionals of the country. However, in this task, the institutions are faced with the challenge of attracting and working with young people of Generation $\mathrm{Y}$, which have characteristics and needs that are not met by traditional teaching methods. Problem-Based Learning (PBL) is an approach evolved in order to study and develop educational alternatives that meet the needs of businesses as well as the new student profile. In addition, actively teaching is not a simple task and becomes more complex when it refers to assess the knowledge gained through this method. Thus, this paper presents the planning, implementation and the assessment method adopted in a course of Industrial Engineering at the Federal University of Itajubá based on PBL. For this study it was adopted the action research method, in which the authors actively participated in all stages of the course, acting as facilitators in the course planning, implementation and monitoring. As a result, it is
\end{abstract}


highlighted in this article, the benefits achieved by all involved through active learning, as well as the strengths and weaknesses of the method. Moreover, improvements are proposed for future courses.

Keywords: Problem-Based Learning. European Project Semester. Active Learning. Engineering Teaching, Assessment methods.

\section{INTRODUÇÃO}

O mundo está passando por um processo de rápidas e profundas transformações, atribuídas à revolução tecnológica e à globalização. Tais transformações desafiam as empresas que, para se manterem competitivas e sobreviverem no mercado, precisam buscar profissionais cada vez mais competentes e completos, exigindo com isso, mudanças na dinâmica de ensino e aprendizagem dos universitários. Além dos conhecimentos tradicionalmente adquiridos em sala de aula, os profissionais, em especial os engenheiros, precisam apresentar habilidades e atitudes exigidas pelo mercado. Nesse sentido, Ribeiro e Mizukami (2005), afirmam que a revolução tecnológica vivenciada afeta também o ensino em Engenharia ao promover uma rápida expansão na base de conhecimento e, ao mesmo tempo, uma obsolescência imprevisível do que se aprende nas Universidades.

De acordo com Dias, Turrioni e Silva (2012), além da expansão no seu campo de atuação, os engenheiros são desafiados durante sua formação por exigências que ultrapassam o conhecimento técnico e envolvem o desenvolvimento de habilidades e atitudes, tais como: liderança, trabalho em equipe, pró-atividade, ética, comprometimento, equilíbrio emocional, flexibilidade e capacidade de decisão e priorização.

Além disso, a entrada de uma nova geração, a Geração $Y$, nas salas de aula e, consequentemente, no mercado de trabalho desafiam ainda mais as empresas e universidades. Segundo Pereira, Treml e Rank (2012), a maioria dos acadêmicos presentes nos cursos de Engenharia pertence a esta geração que, frequentemente, expressam certa resistência e exigem mais das aulas tradicionais. Os jovens da Geração Y são mais impulsivos e destemidos e não imaginam um mundo sem tecnologia e comunicação instantânea, dando a eles maior capacidade de serem multitarefas e de viverem em um ritmo mais acelerado (OLIVEIRA, 2009). 
Desta forma, as mudanças contínuas enfrentadas pelas empresas e o desafio das universidades em conseguir atrair a atenção dos jovens da Geração Y, requerem adaptações na forma de ensinar. De tal modo, é preciso repensar o ensino em Engenharia como um todo, de forma a se adaptar ao novo ambiente e superar metodologias incompatíveis com os desejos dos atuais graduandos e necessidades do mercado profissional.

Dias, Turrioni e Silva (2012) sugerem a Aprendizagem Baseada em Problemas ( $\mathrm{ABP}$ ), que vem do inglês Problem Based Learning ( $\mathrm{PBL}$ ), como uma abordagem pedagógica ativa, amplamente estudada e aplicada no ensino das ciências médicas, e que vem sendo aplicada no ensino da Engenharia. Esse método centra-se no aluno e favorece o desenvolvimento de habilidades e atitudes. Porém, Cardoso (2011) ressalta que, apesar da ABP já ser utilizada em áreas como medicina há vários anos, no ensino em Engenharia é algo ainda relativamente raro. Atrelado a isso, recentemente tem sido discutido o European Project Semester (EPS), em português, Projeto Semestral Europeu, outro método de ensino ativo, porém com foco maior no ensino em Engenharia.

Contudo, apesar dos benefícios para o ensino descritos pelos educadores através da adoção de metodologias de ensino ativo, avaliar a evolução do conhecimento e se os objetivos de aprendizagem foram alcançados de forma satisfatória, dentro desta nova forma de ensinar, não é uma tarefa simples, pois cada um possui sua própria maneira de adquirir conhecimentos e habilidades, seja através de estudos ou de experiências vividas.

Considerando a relevância e a necessidade de novas práticas de ensino em Engenharia que favoreçam a formação de profissionais capacitados, bem como as dificuldades em avaliar a absorção do conhecimento dentro destas novas metodologias, este trabalho visa apresentar o planejamento, a condução e o método de avaliação de uma disciplina baseada na ABP para o curso de Engenharia de Produção da Universidade Federal de Itajubá (UNIFEI). Com isso, o objetivo geral se desdobra nos seguintes objetivos específicos: (i) apresentar a criação da disciplina "Projeto Semestral em Engenharia de Produção" na UNIFEI; (ii) discutir as etapas propostas para a condução da disciplina; (iii) apresentar o método de avaliação 
adotado, bem como seus pontos fortes e fracos; (iv) destacar as dificuldades encontradas durante a execução do curso e (iv) discutir os resultados alcançados e propor melhorias.

\section{REVISÃO BIBLIOGRÁFICA}

Atualmente, as aulas ministradas nos cursos de Engenharia no Brasil acompanham um modelo tradicional de ensino, onde o professor, centro das atenções, é responsável por transmitir todo o conhecimento; enquanto os alunos são apenas os receptores da informação.

Para aperfeiçoar este método de ensino, a ABP vem sendo difundida, cada vez mais, nos cursos de nível superior e principalmente nas áreas de Engenharia. Campos; Dirani e Manrique (2011) ressaltam o inexpressivo número de trabalhos científicos envolvendo a ABP, na Engenharia, em comparação com a quantidade de cursos existentes, nesta área, no Brasil. Em especial no campo da Engenharia, os métodos de ensino ativo devem ser cada vez mais incentivados, pois neles os estudantes atuam como profissionais e precisam solucionar os problemas como verdadeiros responsáveis por eles.

Segundo Branda (2009), a ABP surgiu no final da década de 1960, na Faculdade de Medicina da Universidade de McMaster, Canadá. Esta estratégia foi criada com intenção de superar a discrepância entre o início do curso, onde a formação era dominantemente teórica, e o final, onde os alunos iniciavam a prática médica. A ABP permitiu o estabelecimento de uma relação prática-teoria-prática como processo de formação dos médicos daquela Universidade.

A ABP, também conhecida como metodologia ativa de ensino, compõe estratégias de uma proposta pedagógica na qual a aprendizagem é desenvolvida em pequenos grupos tutorados, onde o professor passa a ser apenas um mediador, permitindo que o aluno busque o melhor caminho para solucionar o problema proposto (MAMEDE, 2001). O ensino através desta abordagem ativa faz com que os alunos desenvolvam suas habilidades profissionais através da resolução de problemas reais. Geralmente, esses problemas são apresentados com informações 
insuficientes, para que os grupos de alunos desenvolvam a melhor solução, podendo com isso gerar mais de uma solução para o mesmo problema, enquanto o professor atua como um facilitador na busca de informações (SAMED e CASSOLO, 2013).

De acordo com um dos pioneiros na aplicação desta metodologia, Barrows (1996), o processo da ABP inicia-se com a apresentação de um problema, onde os alunos, divididos em grupos, tentam solucioná-lo utilizando todo conhecimento e ferramentas que dispõem. A partir daí, os alunos levantam hipóteses, examinam e discutem como solucionar o problema, baseando-se nos dados apresentados. Em seguida, determinam quais conceitos não foram compreendidos e explorados e determinam as responsabilidades de cada membro do grupo, priorizam prazos e as fontes de pesquisa para, então, compartilharem os resultados com o grupo. Ao final desta jornada, eles devem chegar a uma solução satisfatória, aplicá-la ao contexto do problema e apresentá-la diante dos demais grupos e, por fim, avaliações do processo, do grupo e de cada aluno são realizadas.

Dentro desta mesma discussão e do modelo proposto por Barrows (1996), Ribeiro (2008a) propõe um ciclo semelhante e simples para a elaboração da ABP, sendo flexível para atender a diferentes objetivos, conforme Figura 1.

Ribeiro (2008a) explica que este método é caracterizado pela aplicação de problemas reais como ferramenta para o desenvolvimento de habilidades para resolução de problemas e assimilação dos conceitos fundamentais sobre a área em questão. Para o ensino superior, a ABP também é um meio eficiente de integrar a teoria com a prática, ou seja, o mundo acadêmico com o mercado de trabalho, o que muitas vezes acontece através de parcerias com empresas, proporcionando assim a evolução de atitudes e posturas profissionais. 
Figura 1 - Ciclo de elaboração da ABP

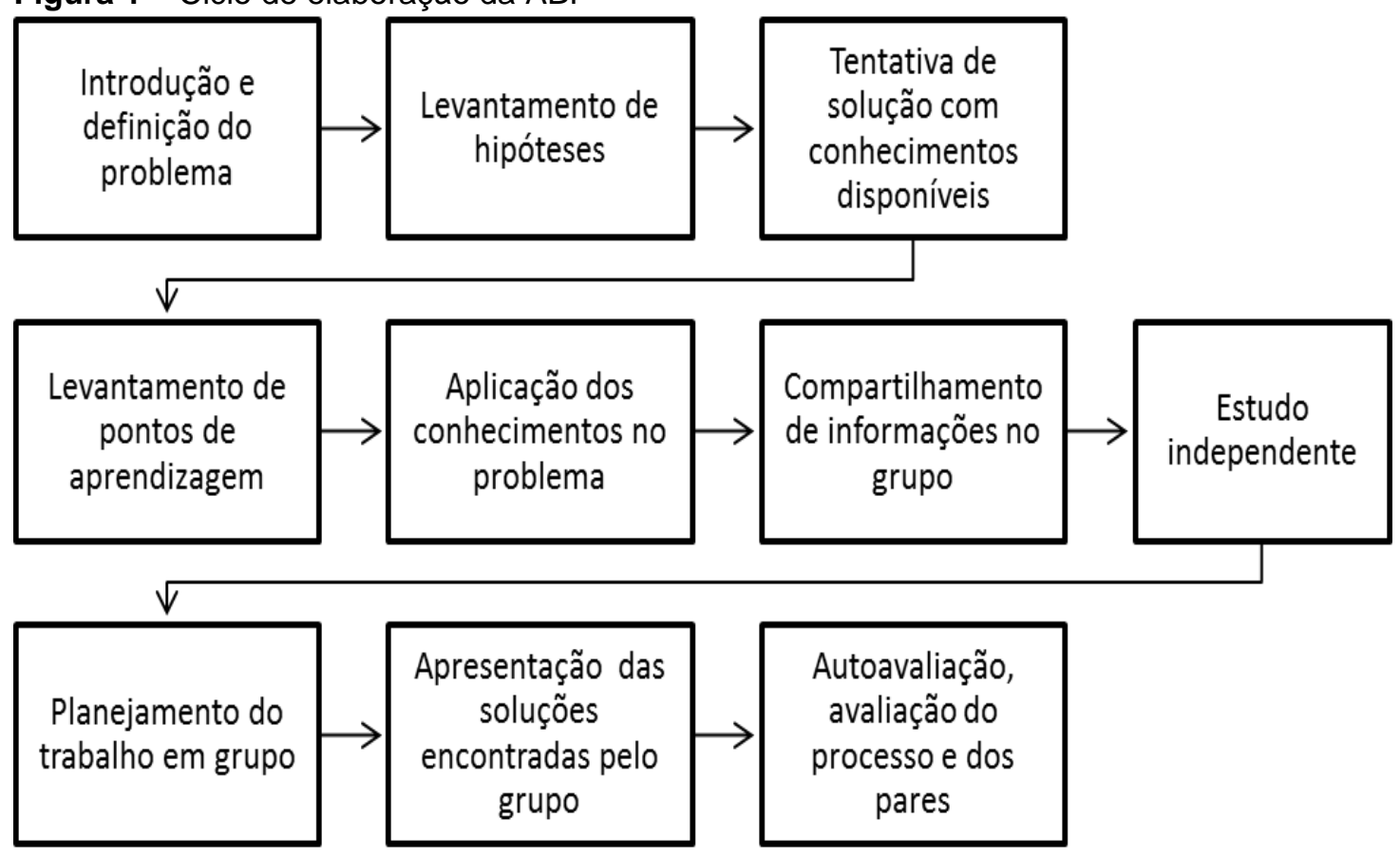

Fonte: Adaptada de Ribeiro (2008a)

Freitas (2012) considera que a ABP exerce um avanço no método de ensino superior devido ao aluno aprender de uma maneira diferente da convencional. Ao colocar o aluno no centro da aprendizagem, ela contribui na aquisição de hábitos de aprendizagem autônoma e, assim, motiva o aluno a desenvolver um senso de responsabilidade e, também, o ajuda a superar a tão criticada separação entre a formação acadêmica (teoria) e a prática profissional. Na engenharia, a prática da ABP vem sendo bem vista por conta de seus resultados que favorecem a formação de profissionais competentes e capacitados para uma atuação imediata no mercado de trabalho. Enemark e Kjaersdam (2009) ressaltam alguns resultados proporcionados pela ABP para seus participantes:

- Maior integração entre a universidade e a empresa;

- Maior integração entre o ensino e a pesquisa;

- Mais soluções interdisciplinares;

- Uso de conceitos atuais;

- Atualização do conhecimento dos professores;

- Incentivo à criatividade e inovação; 
- Expansão de habilidades em desenvolvimento de projetos e de comunicação; e,

- Favorecimento de um aprendizado eficaz.

Ribeiro (2008b) cita, em seus estudos, benefícios resultantes da aplicação da ABP no ensino em Engenharia, como: capacidade de tornar a aprendizagem mais dinâmica e prazerosa, desenvolvimento de habilidades comunicativas e sociais e desenvolvimento da responsabilidade dos alunos no cumprimento de prazos e planos de estudo.

No entanto, a metodologia da ABP não deve ser abordada como uma solução para todos os problemas na educação em Engenharia, pois alguns alunos podem não se adaptar a esta natureza autônoma e participativa, mesmo que para a formação destes profissionais tais habilidades sejam necessárias. Esta autonomia é um pouco mais complicada de alcançar, pois para isso é necessário uma turma com maior nível de maturação e um professor que instigue mais o pensamento crítico para o desenvolvimento do aluno por meio de questionamentos e discussões entre os integrantes do grupo (CARMO, BARROSO e ALBERTIN, 2010). Outras desvantagens a serem consideradas são: o fato de não existirem problemas para todos os conteúdos do currículo e ausência de tempo para o desenvolvimento dos demais conteúdos por conta da abrangência do projeto.

Como fruto da ABP, em 1995 na Dinamarca, surgiu para a Engenharia o EPS. Idealizado pelo Dr. Arvid Andersen, este conceito trabalhou com equipes internacionais com o intuito de desenvolver trabalhos em projetos multidisciplinares para treinar os estudantes de Engenharia a trabalhar em equipes e obterem resultados que solucionassem os problemas propostos. O EPS traz em sua essência duas principais áreas de orientação: a orientação para a solução do problema e, também, para o desenvolvimento do curso. Os alunos passam a desenvolver e aprimorar habilidades fundamentais para o mercado de trabalho e, ao fim do projeto, serão capazes de se tornarem profissionais que sabem trabalhar em equipe, diferenciando cooperação e concorrência, e de adquirir características como responsabilidade profissional e comprometimento (ANDERSEN, 2011). 
O criador do EPS ressalta como suas principais características que o projeto na área de Engenharia seja formado por grupos de quatro a cinco alunos em parceria com empresas e que a avaliação se mantenha individual, porém a apresentação oral, o conteúdo técnico e comunicativo do relatório, o exame individual oral e o desempenho do grupo serão utilizados como base para a nota final. Outro importante ponto do EPS são alguns dos resultados atingidos pelos seus participantes no final do semestre, nos quais se destacam segundo Andersen (2011):

- Desenvolvimento de percepção e compreensão interdisciplinar;

- Desenvolvimento de habilidades técnicas;

- Os alunos se veem responsável pelo próprio aprendizado; e,

- Aumento da criatividade, conhecimento e comunicação.

A qualidade profissional e acadêmica da ABP pode ser afirmada através de um bom sistema de avaliação, pois é a avaliação da aprendizagem que vai mensurar o nível de conhecimento absorvido pelo aluno (ENEMARK e KJAERSDAM, 2009). Para a aplicação deste estudo, a avaliação formativa é a que melhor se relaciona e estima a aprendizagem baseada em problemas. Almeida (1997) traz que a avaliação formativa é favorável para o ensino e para a aprendizagem, pois consiste em um tipo de avaliação que ocorre durante todo o processo de ensino, permitindo verificar se a aprendizagem está de fato sucedendo. Ela também identifica as carências da aprendizagem para que modificações, incorporações e aperfeiçoamentos possam ser feitos no programa, a fim de suprilas. A avaliação formativa fornece os melhores resultados quanto às informações sobre os itens aprendidos quando os testes não resultam em notas.

Chiavenato (2008) aponta que uma avaliação realizada por múltiplas fontes é mais rica por produzir uma variedade de informações advindas de todos os lados e funciona também para garantir o ajuste e a adaptação das pessoas às várias demandas que ela pode receber em seu ambiente de trabalho. A avaliação 360 graus apresenta-se como uma forma de resposta bem estruturada ao desempenho do aluno avaliado. Ela se adequa também na avaliação formativa presente na área acadêmica e principalmente em uma abordagem como a ABP, que incentiva os 
alunos a desenvolverem suas habilidades diante de situações mais próximas da realidade. Em geral, o termo "360 graus" é aplicado em ambientes empresariais, para medir a avaliação feita por pares de trabalho, superiores, subordinados, clientes e pelo próprio funcionário (REIS, 2010).

Independente do tipo de avaliação aplicada é evidente a sua importância dentro do ambiente acadêmico tanto para o docente, no desenvolvimento de métodos de ensino, quanto para o aluno, para a percepção da aprendizagem. A avaliação proporciona ao estudante uma revisão e um levantamento de seu desempenho e para o professor, ela resulta em uma orientação para sua metodologia de ensino, de modo a incentivar seu aperfeiçoamento contínuo. Além das formas de avaliação descritas acima, em resumo, os tipos mais comuns encontram-se dispostos na Tabela 1.

Tabela 1 - Tipos de avaliação

Tipos de avaliação

\begin{tabular}{|c|c|}
\hline $\begin{array}{c}\text { Autoavaliação } \\
\text { Por pares } \\
\text { Tradicional ou Direta }\end{array}$ & $\begin{array}{l}\text { Os avaliados ponderam o seu próprio desempenho, } \\
\text { preenchendo formulários que realizam os julgamentos sobre a sua } \\
\text { performance no trabalho ou no projeto, com base nos parâmetros } \\
\text { fornecidos pelo avaliador. } \\
\text { Os integrantes da equipe avaliam a equipe como um todo } \\
\text { e cada pessoa individualmente, deixando a responsabilidade pelo } \\
\text { sucesso do trabalho por conta do grupo. } \\
\text { O responsável pela avaliação é o avaliador direto } \\
\text { (professor), que assume a função e o compromisso de emitir um } \\
\text { parecer sobre o desempenho de todos os seus avaliados. } \\
\text { Parecer feito sobre uma pessoa ou grupo na realização de } \\
\text { um trabalho ou projeto, com a intenção de avaliar o seu } \\
\text { desempenho. Nesta ação são revelados os pontos fortes e as } \\
\text { deficiências do trabalho executado tendo em vista seu crescimento } \\
\text { pessoal e profissional. }\end{array}$ \\
\hline Feedback & \\
\hline
\end{tabular}

Fonte: Bayot (2011) e Chiavenato (2008). Elaborado pelos autores primeiro aborda publicações em todas as áreas de ensino no Brasil pela base da 
Scientific Eletronic Library Online e o segundo aborda publicações apenas no campo da Engenharia de Produção pelos Anais do Encontro Nacional de Engenharia de Produção, onde é possível perceber a pequena quantidade de estudos e publicações no Brasil, sobre a ABP na Engenharia de Produção. Em ambas as pesquisas foram utilizadas o tema "Aprendizagem Baseada em Problemas", considerando apenas publicações em português e nos últimos cinco anos no Brasil.

Tabela 2 - Aplicação da ABP no Brasil

\begin{tabular}{|c|c|}
\hline Scielo ${ }^{\circledR}$ - Scientific Eletronic Library Online & $\begin{array}{l}\text { ENEGEP - Encontro Nacional de Engenharia } \\
\text { de Produção }\end{array}$ \\
\hline $\begin{array}{l}\text { Palavra-chave: Aprendizagem Baseada em } \\
\text { Problemas }\end{array}$ & $\begin{array}{l}\text { Palavra-chave: Aprendizagem Baseada em } \\
\text { Problemas }\end{array}$ \\
\hline País: Brasil & País: Brasil \\
\hline Ano: 2009 a 2013 & Ano: 2009 a 2013 \\
\hline Idioma: Português & Idioma: Português \\
\hline Resultado: 27 publicações & Resultado: 3 publicações \\
\hline Áreas & Resultado \\
\hline Medicina & 2013 \\
\hline Enfermagem & 2012 \\
\hline Terapia Ocupacional & 2011 \\
\hline $\mathrm{ABP}$ & 2010 \\
\hline Química & 2009 \\
\hline
\end{tabular}

Fonte: Elaborada pelos autores

O Brasil ainda tem muito a amadurecer em seu método de ensino para que a aplicação desta forma de aprendizagem seja concretizada e com isso proporcione aos alunos uma aprendizagem efetiva que os prepare para uma boa carreira profissional, visto que os atuais e futuros profissionais estão cada vez menos focados em questões tradicionais de tomada de decisão e liderança. Eles buscam formas de conduzir as pessoas a alcançar os objetivos traçados através de novos métodos de gestão, sem se apegarem aos modelos tradicionais adotados pelas gerações anteriores. 


\section{MÉTODO DE PESQUISA}

O método de pesquisa adotado neste trabalho foi a pesquisa-ação, por possuir uma dimensão participativa, onde os vários atores implicados na situação pesquisada foram levados a identificar os problemas e a propor ações concretas, gerando assim um conhecimento entrelaçado com a prática. O termo pesquisa-ação refere-se à pesquisa como a produção do conhecimento e à ação como uma modificação intencional da realidade trabalhada. Na pesquisa-ação, a geração de conhecimento é conduzida pela prática, porém com a alteração da realidade trabalhada simultaneamente (MELLO et. al., 2012).

Para a condução do trabalho, foi adotada a estrutura proposta por Coughlan e Coghlan (2002), conforme a Figura 2. Thiollent (2011) destaca que a pesquisa-ação pode ser realizada em um único ciclo ou separada em ciclos menores.

Considerando um único ciclo de pesquisa-ação, este trabalho englobou as seguintes etapas:

a) Coleta de dados: coleta de informações sobre os métodos de ensino ativo, as necessidades da empresa parceira e as exigências curriculares da Universidade;

b) Devolução e análise dos dados: discussões entre empresa e Universidade sobre os métodos de ensino existentes, a proposta de disciplina a ser criada e o contrato para execução da mesma;

c) Planejamento das ações: planejamento da disciplina e dos projetos que fariam parte da mesma,

d) Implementação e monitoramento: criação da disciplina eletiva na grade curricular da Engenharia de Produção na UNIFEI e sua efetiva condução no segundo semestre de 2013;

e) Avaliação: avaliação dos resultados obtidos com a disciplina, sob o ponto de vista dos alunos, tutores, Universidade e empresa.

Por outro lado, ao se pensar em pequenos ciclos, deve-se considerar a execução da disciplina, a qual pode ser dividida em quatro ciclos de um mês, onde os estudantes, através de visitas e análise de documentos, coletavam dados 
necessários para desenvolver soluções dos projetos propostos pela empresa e os tutores, bem como o professor, realizavam entrevistas exploratórias e observações para analisarem o desenvolvimento dos projetos como um todo.

Figura 2 - Estrutura para condução da pesquisa-ação

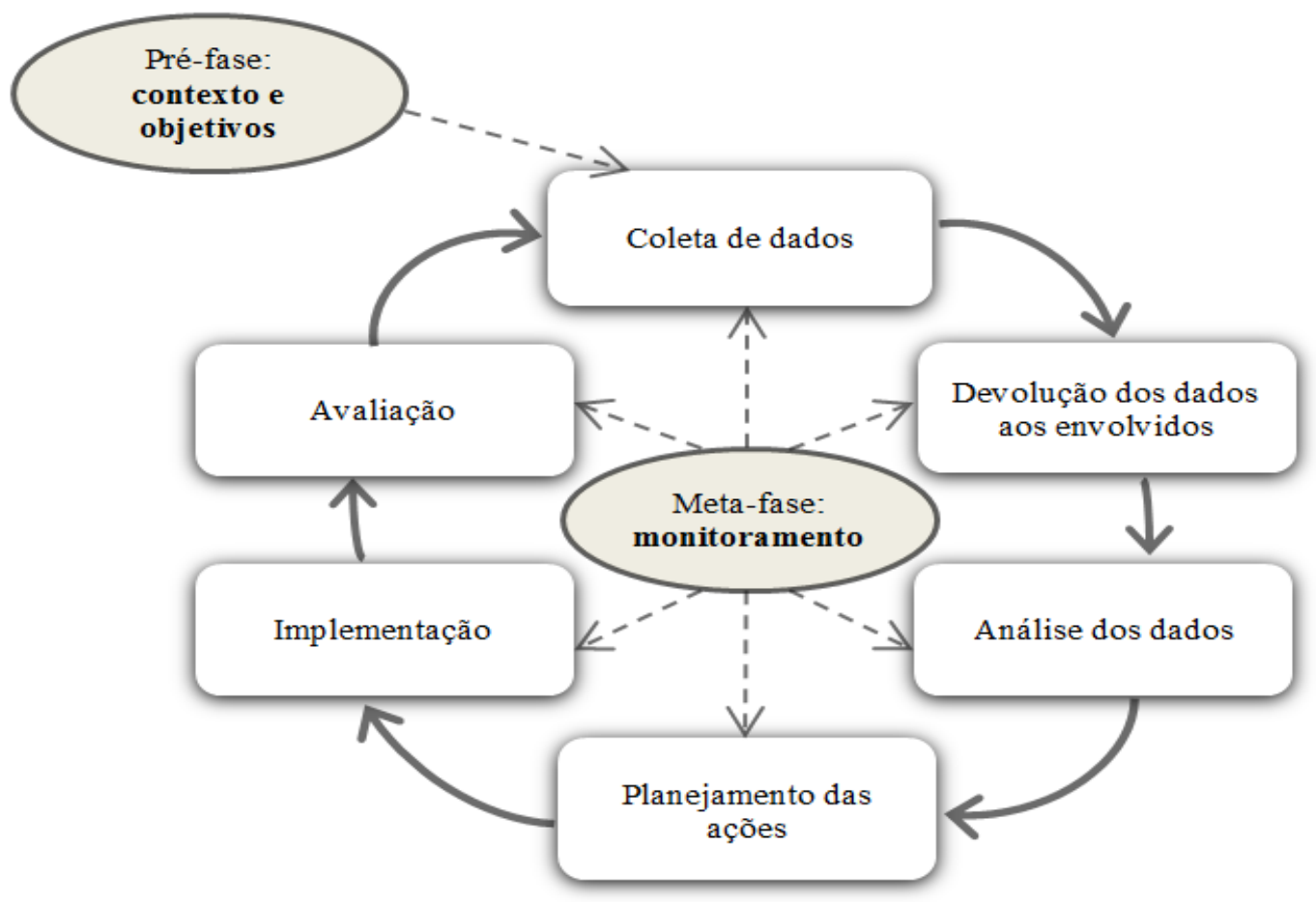

Fonte: Traduzido de Coughlan e Coghlan (2002)

\section{DESENVOLVIMENTO}

\subsection{Criação da disciplina "Projeto Semestral em Engenharia de Produção"}

A UNIFEI vem aplicando a ABP no curso de Engenharia de Produção através da disciplina Gestão da Qualidade como relatado em Dias, Turrioni e Silva (2012). Essa busca por novas disciplinas que utilizam a aprendizagem ativa fez com que sucedesse a criação da disciplina "Projeto Semestral em Engenharia de Produção" no $2^{\circ}$ semestre de 2013.

Essa disciplina foi concebida em parceria entre a UNIFEI e uma empresa multinacional localizada no Vale do Paraíba, São Paulo, com o intuito de que os 
alunos pudessem resolver problemas reais da empresa, ambientando-se ao meio empresarial, desenvolvendo suas habilidades e despertando seu interesse em trabalhar na organização futuramente.

O contato inicial entre universidade e empresa aconteceu no final de 2012, quando foram discutidos os assuntos jurídicos envolvidos na parceria como, por exemplo, o sigilo de informações da empresa, bem como o compromisso da organização em disponibilizar seus funcionários e infraestrutura para que os alunos pudessem conduzir os projetos. Internamente, na universidade, foi aprovada no segundo semestre de 2013 a criação da nova disciplina, optativa aos alunos do $8^{\circ}$ período do curso de Engenharia de Produção. E internamente, na empresa, foram levantados os problemas que deveriam ser resolvidos e apresentados aos alunos.

\subsection{Etapas e atividades estabelecidas para a condução da disciplina}

No primeiro dia de aula, o professor responsável pela disciplina apresentou aos alunos o calendário de atividades da disciplina incluindo as datas das quatro visitas pré-agendadas à empresa.

O professor também informou que haveria encontros na universidade, às sextas-feiras, no período da tarde, onde os alunos poderiam utilizar o tempo para trabalharem na resolução dos problemas propostos e o professor abordaria conceitos e teorias apontados pelos alunos como necessários à elaboração das soluções. A Figura 3 exibe os alunos, tutores e professor em uma das reuniões realizadas. 
Figura 3 - Foto tirada em uma reunião entre alunos, tutores e professor

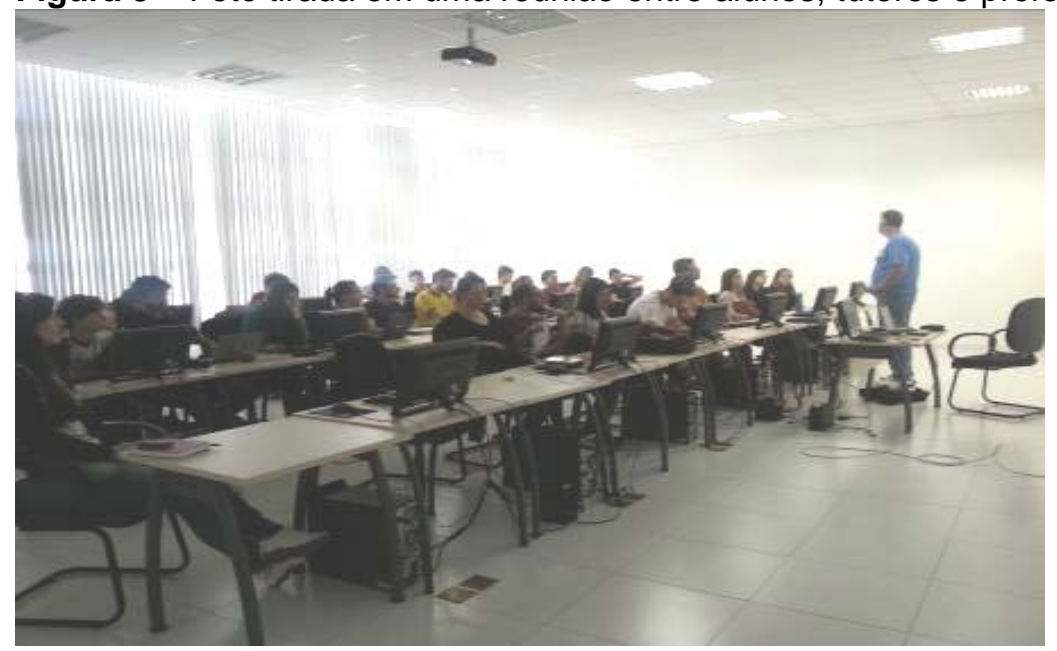

Fonte: Autores

Com o número de alunos matriculados na disciplina, realizou-se um sorteio e os alunos foram divididos em quatro grupos de oito alunos cada. Através de outro sorteio, os quatro projetos propostos pela empresa foram sorteados para cada um dos grupos de modo a não privilegiar alguma equipe. Os projetos sorteados foram apresentados aos alunos e envolviam as seguintes áreas: Lean Manufacturing, Análise de Controle de Custos, Gestão de Inventário e Redução de Despesas de Embalagem.

Cada grupo seria monitorado por dois tutores, sendo um da empresa e outro da universidade. Os tutores da universidade eram alunos de pós-graduação convidados a ajudar o professor na condução da disciplina, de modo a propiciar um melhor monitoramento dos grupos. Os tutores da empresa, denominados "embaixadores", eram compostos por funcionários que trabalhavam diretamente nas áreas afetadas pelos problemas propostos e, assim, poderiam repassar todas as informações e contatos necessários para que os alunos pudessem entender o problema.

Formadas as equipes e com o escopo do projeto já definido, deu-se início às atividades. Como primeira atividade, os alunos estabeleceram as responsabilidades de cada integrante e definiram o cronograma das atividades a serem entregues. Para isso, foram utilizadas ferramentas de gerenciamento de projetos como Matriz RACI e SIPOC. 
A primeira visita oficial à empresa aconteceu em 16 de agosto de 2013 quando cada grupo conheceu o seu respectivo embaixador e pôde esclarecer dúvidas em relação ao projeto proposto. Também foram traçadas metas que os alunos deveriam atingir até a próxima visita oficial.

Alguns grupos sentiram a necessidade de realizar mais visitas à empresa. Deste modo, cada grupo agendou com o seu respectivo embaixador visitas extras. Com o intuito de minimizar a ida dos alunos à empresa, foram agendadas também reuniões semanais com os embaixadores via telefone, Skype ${ }^{\circledR}$ ou através do software $W e b e x ®$ que auxilia em conferências pela internet.

Para a condução do projeto, os alunos tiveram, então, que buscar soluções viáveis através de consulta e pesquisa bibliográfica, orientações e brainstorming com professores, tutores e embaixadores, mas de modo que nenhuma experiência externa interferisse ou influenciasse na decisão final dos alunos.

\subsection{Métodos de avaliação da disciplina}

A avaliação formativa de disciplinas baseadas na ABP, amplamente discutida por especialistas, visa monitorar o processo ensino-aprendizagem dos alunos e professores (CAMPOS, DIRANI e MANRIQUE, 2011). Essa avaliação atribui aos estudantes um papel de responsabilidade em analisar os seus avanços no projeto e dos seus colegas de grupo, não focando apenas no professor como o responsável por avaliar o processo de aprendizagem.

$\mathrm{Na}$ disciplina "Projeto Semestral em Engenharia de Produção", o professor responsável propôs que avaliações periódicas fossem realizadas durante todo o semestre com o intuito de monitorar a participação de cada aluno em seu grupo de trabalho. Com base nesta definição, os alunos foram avaliados de quatro maneiras diferentes:

- Avaliação por pares: cada integrante do grupo avaliou os demais integrantes do mesmo grupo considerando os dezoito critérios listados na Tabela 3, com notas de 0-10, sem repetição, ou seja, cada aluno teve que ordenar os seus colegas de equipe do melhor para o pior em todos os 
critérios. Desta maneira, seria possível perceber a diferença das participações dos alunos dentro do grupo, buscando evitar possíveis interferências de amizades na avaliação;

- Avaliação tutor-aluno: através de avaliações semanais, os tutores avaliaram a evolução do projeto e o desempenho individual de cada aluno do seu grupo. Nesta disciplina, os tutores representaram o olhar do professor em cada grupo, já que este não poderia estar presente nos quatro grupos ao mesmo tempo. As avaliações realizadas pelos tutores foram: 1) a cada reunião semanal com seu grupo, o tutor pontuou cada aluno, com notas de 0-10, sem repetição, com o intuito de diferenciar a participação de cada aluno durante a evolução do projeto, 2) avaliação da pré-apresentação oral de cada um dos grupos, para os tutores, embaixadores e alguns funcionários das áreas relacionadas ao problema, realizada na terceira visita à empresa, com o intuito de verificar se os alunos conseguiriam transmitir a ideia geral do trabalho. No dia da apresentação final, haveria um público diversificado e que não possuía um entendimento sólido do problema exposto, sendo assim, nesta apresentação prévia cada tutor avaliou os quatros grupos considerando os dezesseis critérios listados na Tabela 4, com notas de 1-6, sem repetição, de acordo com a escala: 6 - extremamente favorável, 5 - muito favorável, 4 - favorável, 3 - quase desfavorável, 2 - desfavorável, 1 extremamente desfavorável;

- Avaliação professor-aluno: avaliações periódicas em que o professor pontuava as entregas de metas previamente estabelecidas e a evolução do projeto a cada semana, com a finalidade de medir se os grupos cumpriram as metas estabelecidas pelos embaixadores da empresa;

- Avaliação embaixador-grupo: avaliações mensais durante as visitas préagendadas em que o embaixador avaliava a evolução das propostas de solução apresentadas pelo grupo. Durante as visitas, cada grupo se reunia com o seu respectivo embaixador para absorver o maior número possível de dados e informações a respeito do problema que a eles foi 
designado para resolver. Com isso, o embaixador conseguia avaliar a evolução do desde a última visita. Os embaixadores também avaliaram, na terceira visita que aconteceu no mês de Outubro, a pré-apresentação dos grupos considerando os mesmos dezesseis critérios avaliados pelos tutores da Universidade e apresentados na Tabela 4.

Tabela 3 - Critérios de avaliação de competências utilizados na avaliação por pares (continua)

\section{Critérios de avaliação}

1. Empatia: Capacidade de se colocar no lugar do outro, enxergando pelos olhos do outro, pelas motivações, interesse e percepções. É perceber sentimentos e emoções no outro e interagir de forma positiva com esses sentimentos e emoções

2. Equilíbrio: Capacidade de manter ponderação e bom senso em situações de imprevistos, adversidade e pressão, comunicando-se de maneira exemplar e conduzindo as ações de forma equilibrada.

3. Comunicação: Capacidade de criar canais de comunicação, recebendo e transmitindo informações de maneira eficaz. Habilidade de influenciar, de convencer. Ter clareza, objetividade e profundidade.

4. Iniciativa: Capacidade de antecipar, decidir e realizar ações de forma empreendedora e responsável, visando suprir e otimizar suas atividades de trabalho.

5. Pró-atividade: Capacidade de se antecipar aos fatos, tendo ações preventivas no sentido de conduzir a equipe a atingir os melhores resultados.

6. Flexibilidade e Inovação: Capacidade de adaptação rápida e situações inesperadas e facilidade de encontrar novas soluções para resolver problemas e adversidade.

7. Planejamento e Organização: Capacidade de organizar e estabelecer ordem de prioridades às tarefas, mesmo diante de situações adversas, e otimizar procedimentos em favor da eficácia em resultados.

8. Tomada de decisão: Capacidade de escolher alternativas adequadas e eficazes para os problemas identificados, comprometendo-se com o resultado, respeitando a hierarquia, visando cumprimento das estratégias organizacional e pautado na missão e valores.

9. Autodesenvolvimento: Capacidade de buscar o seu próprio desenvolvimento profissional.

10. Ética: Capacidade de agir com integridade e justiça, respeitando as pessoas e as normas.

11. Comprometimento: Capacidade de disponibilizar todo o potencial em prol dos objetivos e metas da organização, dando suporte com total dedicação e empenho.

12. Responsabilidade: Capacidade de responder por suas ações, cumprir tarefas, deveres e normas, agir com zelo e ser pontual.

13. Consciência ecológica e Sustentabilidade ambiental: Capacidade de agir de forma consciente, evitando o desperdício, utilizando os recursos de maneira econômica, sendo socialmente justo, buscando aceitação cultural e preservando o meio ambiente.

14. Relacionamento interpessoal: Capacidade de se relacionar de forma construtiva com a equipe, demonstrando consideração e respeito pelos colegas, promovendo a união e integração de todos e se sentindo parte da equipe e compartilhando problemas e soluções.

15. Espírito de equipe: Desenvolver uma relação de complementariedade com os membros da equipe, ser capaz de promover divisões justas de tarefas, ter iniciativa para cooperar, estar comprometido com os objetivos, compartilhar e comemorar metas atingidas e resultados. 
Tabela 3 - Critérios de avaliação de competências utilizados na avaliação por pares (conclusão)

\section{Critérios de avaliação}

\begin{tabular}{l} 
16. Foco no cliente: Capacidade de tomar providências rápidas diante de problemas, \\
conflitos, visando o melhor atendimento das necessidades do cliente. \\
\hline 17. Foco em resultados: Capacidade de pautar suas ações no alcance dos resultados \\
esperados pela organização. \\
18. Orientação pela qualidade: Capacidade de agir buscando a qualidade do serviço \\
prestado e o atendimento ao cliente, visando obter resultados com excelência.
\end{tabular}

Fonte: Autores

Tabela 4 - Critérios de avaliação da pré-apresentação utilizados pelos tutores e embaixadores

\section{Critérios de avaliação}

01. A exposição foi estruturada de forma clara?

02. O apresentador soube conduzir a sequência entre os tópicos dos slides?

03. A ideia principal do trabalho foi apresentada deforma clara e compreensível?

04. Os exemplos apresentados foram relevantes?

05. Os exemplos apresentados foram interessantes?

06. O ritmo da apresentação foi adequado?

07. O volume de informação contido na apresentação foi adequado?

08. O tom de voz do apresentador foi adequado?

09. Os slides foram eficientemente utilizados?

10. A apresentação foi bem preparada?

11. A apresentação foi interessante e motivadora?

12. O contato visual do apresentador com o público foi correto e adequado?

13. O apresentador conseguiu prender a atenção do público?

14. O apresentador mostrou/resumiu os pontos principais da apresentação?

15. O apresentador demonstrou confiança e conhecimento no assunto apresentado?

16. O tempo gasto na apresentação foi bem gerenciado?

Fonte: Autores

\subsection{Análise do método de avaliação adotado na disciplina}

De acordo com a percepção dos autores deste trabalho, o método de avaliação adotado para a disciplina "Projeto Semestral em Engenharia de Produção" proporcionou uma ampla análise do desempenho dos alunos por conta da aplicação de uma avaliação 360 graus que pôde fazer uso de várias perspectivas (pares, professor, tutores e embaixadores). A não repetição de notas foi reconhecida como um ponto positivo, pois propiciou uma diferenciação entre os grupos e entre os integrantes de cada grupo, fazendo com que os alunos se posicionassem com maturidade ao avaliar os colegas de equipe por meio da avaliação por pares. Por menor que tenha sido essa diferenciação foi importante para os alunos gerarem um 
olhar crítico, já que tiveram que diferenciar os colegas de equipe entre o melhor e o pior dentre vários critérios.

A avaliação por pares (Tabela 3) proporcionou aos autores uma importante análise dos alunos, principalmente pelo fato de ter sido realizada pelas pessoas que participaram diretamente do projeto e que estavam em constante contato com os demais integrantes. Um dos pontos interessantes que foi destacado, foi a identificação de uma combinação de notas entre os integrantes do grupo 4, fazendo com que todos os alunos alcançassem a mesma média de notas demonstrando falta de maturidade e seriedade do grupo com a avaliação do projeto, pois com isso perderam a oportunidade de avaliar corretamente aquele aluno que se destacou dentro do grupo e, também, aquele que não participou ativamente das atividades. Ao ser detectada a combinação de notas, o professor teve uma conversa com os integrantes do grupo explicando a importância da avaliação correta para o crescimento deles e do projeto e, após esta conversa, os alunos decidiram refazer a avaliação. Outro ponto destacado da avaliação por pares foi o fato de que a avaliação obtida por cada um dos alunos representou fielmente a percepção dos tutores sobre o grupo, ou seja, o monitoramento realizado pelos tutores resultou no mesmo ponto de vista dos alunos que estavam participando ativamente da execução dos projetos.

Sendo assim, o método de avaliação utilizado permitiu a abrangência dos três pontos citados por Almeida (1997): a avaliação do grau de conhecimento adquirido pelo aluno em relação ao programa de ensino; a avaliação da evolução comportamental em relação ao conteúdo aprendido e vivenciado e a avaliação formativa ao levantar a efetividade da aprendizagem e do conhecimento obtido.

\subsection{Dificuldades encontradas durante a execução da disciplina}

Apesar da grande importância e dos benefícios do ensino baseado na ABP, implementá-la ainda é um grande desafio, pois o aluno historicamente assume uma postura passiva na sala de aula e o professor, até então, sempre foi o centro das ações. Quando os papeis se invertem e as ações passam a serem centradas no 
aluno, algumas limitações surgem podendo comprometer o resultado final do projeto.

O professor responsável e os tutores da disciplina identificaram alguns dos principais problemas que ocorreram nos quatro grupos. A primeira dificuldade foi o alinhamento de escopo e linguagem, pois os grupos demandaram muito tempo para entender com detalhes o problema que a empresa almejava resolver já que a dinâmica e a linguagem empresarial eram fatores desconhecidos dos alunos até então.

Outra dificuldade foi a conciliação de agendas e prioridades para ambas as partes (empresa $x$ alunos). Os alunos alegaram que o desempenho do projeto poderia ter sido melhor se não fossem as preocupações do final de curso como, por exemplo, as dinâmicas e entrevistas de estágio e os trabalhos finais de conclusão do curso. Também não foi fácil para eles conciliarem um horário para reunir o grupo com o seu respectivo embaixador para a discussão do andamento do projeto. A empresa também reconheceu que ocorreram algumas falhas como, por exemplo, a falta de backup de funcionários envolvidos no projeto para que, assim, os alunos não ficassem muito tempo na espera de informações já que as atividades diárias dos funcionários e as mudanças dentro da empresa influenciaram no desenvolvimento das atividades.

A distância entre a empresa e a universidade também foi apontada pelos alunos como um fator limitante ao acesso mais rápido a informações precisas e detalhadas, já que apenas quatro visitas oficiais foram agendadas.

Por fim, também foi apontada a dificuldade de liderança em algumas equipes já que houve resistência por parte de alguns integrantes em respeitar a hierarquia estabelecida, isto é, as posições e responsabilidades de cada integrante, o que sobrecarregou os integrantes mais responsáveis e comprometidos com a disciplina.

\subsection{Proposta de melhoria para o método de avaliação}

Todo método aplicado pela primeira vez em uma determinada situação está sujeito a um levantamento de pontos positivos e negativos. Quanto ao processo de 
avaliação como pontos positivos, os autores destacam que a realização da avaliação durante todo o processo de ensino permitiu verificar a evolução da participação dos alunos nas atividades; a identificação e o preenchimento de lacunas de conhecimentos apresentados pelos alunos e a percepção de seu amadurecimento comportamental, aprendendo a receber feedbacks e críticas construtivas. Por parte dos docentes, o professor esteve constantemente informado das condições em que se encontrava o processo de ensino podendo assim atualizar 0 aluno periodicamente sobre o seu rumo na disciplina e no projeto, de modo que eles tivessem tempo hábil para ajustar sua postura diante do aprendizado.

Como propostas de melhorias para o método de avaliação, considerando os objetivos da metodologia de ensino ativo, que incluem o desenvolvimento de competências técnicas, comportamentais e gerenciais nos alunos, sugere-se a divisão dos critérios de cada avaliação (por pares, tutor-aluno, embaixador-equipe e professor-aluno) em áreas de competências, que compreendem o conjunto de conhecimentos, habilidades e atitudes ( $\mathrm{CHA})$. Além disso, para minimizar as fraquezas identificadas propõe-se: adotar, além da escala quantitativa de nota, uma escala qualitativa em todas as avaliações, como, por exemplo, foi seguido na avaliação realizada pelos embaixadores e tutores (Tabela 4), onde 1 significava extremamente desfavorável e 6 extremamente favorável; desenvolver um roteiro de perguntas para que os alunos possam fazer uma auto avaliação e questionários para a avaliação do método de ensino e do desempenho dos tutores, embaixadores e professor; e um checklist para auxiliar os tutores na padronização da avaliação realizada por eles. Por fim, recomenda-se a adoção de ferramentas mais dinâmicas para realização das avaliações, como os questionários eletrônicos que podem ser aplicados através de sites como o Survey Monkey®.

\section{CONCLUSÃO}

A apresentação final do "Projeto Semestral em Engenharia de Produção" ocorreu em 29 de novembro de 2013, onde os alunos apresentaram para os embaixadores, gerentes e diretores da empresa, assim como para professores e 
para o pró-reitor de graduação da Universidade, as soluções desenvolvidas e seus resultados alcançados. Os responsáveis da empresa analisaram, então, cada solução, avaliando os resultados como positivos e demonstrando interesse em implementar cada solução proposta em suas respectivas áreas. Além disso, o projeto possibilitou o surgimento de ideias e propostas diferentes daquelas usualmente pensadas pelos funcionários que estão no contato diário do problema.

Por parte da Universidade, os docentes também ficaram muito satisfeitos com os resultados, planejando estender a disciplina, incialmente planejada apenas para os alunos de Engenharia de Produção, para alunos das diversas engenharias da instituição nos próximos períodos e, futuramente, até mesmo abranger alunos de instituições diferentes para se assemelhar cada vez mais ao EPS mencionado na Seção 2. Há ainda como resultado a formação de profissionais melhor qualificados que destacarão a universidade no cenário da educação superior do país. É importante notar, também, que o projeto vai de encontro com os princípios inovadores propostos por Brasil (2009) para a estrutura curricular das Engenharias.

Do ponto de vista dos tutores, alunos de pós-graduação da UNIFEI, destacase como positivo seu contato mais próximo à sala de aula, muitas vezes não possibilitado no dia-a-dia da pesquisa e, mais importante que isso, à prática de ensino ativo, cuja metodologia é mais moderna e dinâmica, porém ao mesmo tempo mais desafiadora e, assim, proporcionando uma melhor formação dos futuros professores do ensino superior do Brasil.

Do ponto de vista dos alunos, a ABP permitiu a familiarização dos mesmos com o ambiente empresarial, antes de sua inserção real no mercado de trabalho, e o desenvolvimento de habilidades não estimuladas normalmente pelo método tradicional de ensino, como: comunicação, trabalho em equipe e foco na resolução de problemas. Desta forma, os estudantes, cuja maioria estava em busca de oportunidades de estágio, sentiram-se melhor preparados para o futuro profissional e para os desafios existentes no processo de seleção das empresas.

Quanto ao método de avaliação adotado na disciplina foi possível concluir que ele se mostrou adequado, por se tratar de um método completo e contínuo, onde os alunos não tiveram seus conhecimentos testados apenas a partir de provas 
ou testes. No processo avaliativo adotado, os alunos foram avaliados sob diversas óticas e em diferentes momentos, minimizando a possibilidade de realizar erros ou "injustiças" na avaliação, permitindo verificar a evolução do conhecimento adquirido e de sua participação nas atividades. Reunir avaliações provenientes de todos os membros do projeto ensinou aos alunos a se adaptarem às várias demandas existentes em um ambiente profissional ou de trabalho em equipe, mas, ao mesmo tempo, ainda existem lacunas no método de avaliação adotado que devem ser melhoradas nas próximas edições da disciplina.

Por fim, os autores acreditam que as dificuldades encontradas pelos alunos durante a disciplina já eram esperadas, uma vez que os envolvidos estavam participando pela primeira vez de um projeto com base no aprendizado ativo. As dificuldades, muitas vezes utilizadas como "desculpa" pelos estudantes, indicam a ausência de características comportamentais exigidas pelo mercado de trabalho atual como: comprometimento, capacidade de priorização de atividades e próatividade.

Assim, destaca-se a importância de que mais disciplinas na Engenharia sejam conduzidas baseadas na abordagem de ensino ativo e espera-se com este trabalho, estimular o interesse e a adoção de mais docentes pela abordagem em questão, bem como é ressaltado no trabalho de Carmo, Barroso e Albertin (2010) que incentiva a utilização de atividades como esta para motivar o aprendizado do aluno, de forma que ele possa enxergar a importância das disciplinas do curso em sua vida profissional.

\section{AGRADECIMENTOS}

Os autores agradecem a Fundação de Amparo à Pesquisa do Estado de Minas Gerais (FAPEMIG), a Coordenação de Aperfeiçoamento de Pessoal de Nível Superior (Capes) e ao Conselho Nacional de Desenvolvimento Científico e Tecnológico (CNPQ) pelo apoio concedido a esta pesquisa. Ressalta-se, também, a gratidão à UNIFEI e à empresa, pela oportunidade de participar do projeto e condução da disciplina. 


\section{REFERÊNCIAS}

ALMEIDA, A. M. F. P. M. Avaliação da aprendizagem e seus desdobramentos. Revista da Rede de Avaliação da Educação Superior, v.2, n.2, p.37-50, 1997.

ANDERSEN, A. A fórmula EPS - Projeto Semestral Europeu. In: CAMPOS, L. C.; DIRANI, E. A. T.; MANRIQUE, A. L. (orgs.). 1. ed. Educação em Engenharia: Novas Abordagens. São Paulo: EDUC, 2011.

BARROWS, H. S. Problem-based learning in medicine and beyond: a brief overview. New Directions for Teaching and Learning, n. 68, p.3-12, 1996.

http://dx.doi.org/10.1002/tl.37219966804

BAYOT, P. C. P. Avaliação por Competência no Mundo Globalizado. In: Anais do VII Congresso Nacional de Excelência em Gestão, Niterói e Rio de Janeiro, RJ, 2011.

BRANDA, L. A. A Aprendizagem Baseada em Problemas - o resplendor tão brilhante de outros tempos. In: ARAÚJO, U. F.; SASTRE, G. (orgs.). Aprendizagem Baseada em Problemas no Ensino Superior. $1^{a}$ ed. São Paulo: Editora Summus, 2009.

BRASIL, MINISTÉRIO DA EDUCAÇÃO. Princípios norteadores das engenharias nos institutos federais. Brasília, 2009.

CAMPOS, L. C.; DIRANI, E. A. T.; MANRIQUE, A. L. Educação em Engenharia. Novas Abordagens. São Paulo: EDUC, 2011.

CARDOSO, I. M. Métodos Ativos de Aprendizagem: o uso do aprendizado baseado em problemas no ensino de logística e transportes. Itajubá: UNIFEI, 2011. 131 p. Dissertação (Mestrado) - Programa de Pós-Graduação em Engenharia de Produção, Universidade Federal de Itajubá, Itajubá, Minas Gerais, 2011.

CARMO, B. B. T.; BARROSO, S. H. A.; ALBERTIN, M. R. Aprendizagem discente e estratégia docente: Metodologias para maximizar o aprendizado no curso de Engenharia de Produção. Revista Produção Online. v.10, n.4. p. 779-817, 2010.

http://dx.doi.org/10.14488/1676-1901.v10i4.474

CHIAVENATO, I. Gestão de Pessoas. 3. ed. Rio de Janeiro: Editora Elsiever, 2008.

COUGHLAN, P.; COGHLAN, D. Action research for operations management. International Journal of Operations \& Production Management, v. 22, n. 2, p. 220-240, 2002. http://dx.doi.org/10.1108/01443570210417515

DIAS, M. C.; TURRIONI, J. B.; SILVA, C. V. O uso do aprendizado baseado em problemas no ensino da engenharia de produção. In: Anais do XXXII Encontro Nacional de Engenharia de Produção (ENEGEP), Bento Gonçalves, RS, Brasil, 2012.

ENEMARK, S.; KJAERSDAM, F. A ABP na teoria e na prática: a experiência de Aalborg na inovação do projeto no ensino universitário. In: ARAÚJO, U. F.; SASTRE, G. (orgs.).

Aprendizagem Baseada em Problemas no Ensino Superior. 1. ed. São Paulo: Editora Summus, 2009. 
FREITAS, R. A. M. Ensino por problemas: uma abordagem para o desenvolvimento do aluno. Educação e Pesquisa, v. 38, n. 2, p. 403-418, 2012.

http://dx.doi.org/10.1590/S1517-97022011005000011

MAMEDE, S. Aprendizagem baseada em problemas: características, processos e racionalidade. Fortaleza: Hucitec, 2001.

MELLO, C. H. P., TURRIONI, J. B.; XAVIER, A. F.; CAMPOS, D. F. Pesquisa-ação na engenharia de produção: proposta de estruturação para sua condução. Produção, v. 22, n. 1, p. 1-13. 2012. http://dx.doi.org/10.1590/S0103-65132011005000056

OLIVEIRA, S. Geração Y: era das conexões, tempo dos relacionamentos. São Paulo: Clube de Autores, 2009.

PEREIRA, L.; TREML, E. E. Z. F.; RANK, S. M. W. A geração Y e os processos de aprendizagem na Universidade: um estudo exploratório no curso de Engenharia Mecânica numa universidade do interior de Santa Catarina. In: ENCONTRO NACIONAL DE ENGENHARIA DE PRODUÇÃO (ENEGEP), 32,. 2012. Anais... Bento Gonçalves, RS, Brasil, 2012.

REIS, G. G. Avaliação $\mathbf{3 6 0}$ graus: um instrumento de desenvolvimento gerencial. 3. ed. São Paulo: Editora Atlas, 2010.

RIBEIRO, L. R. C.; MIZUKAMI, M. G. N. Student Assessment of a Problem-Based Learning Experiment in Civil Engineering Education. Journal of Professional Issues in Engineering Education and Practice, v. 131, p. 13-18, 2005. http://dx.doi.org/10.1061/(ASCE)1052$\underline{3928(2005) 131: 1(13)}$

RIBEIRO, L. R. C. Aprendizagem baseada em problema (PBL) na educação em engenharia. Revista de Ensino de Engenharia, v. 27, n. 2, p. 23-32, 2008a.

RIBEIRO, L. R. C. Aprendizagem baseada em problemas (PBL): uma implementação na educação em engenharia na voz dos atores. 2008b. Tese (Doutorado em Educação), Universidade Federal de São Carlos, São Carlos, 2008b.

SAMED, M. M. A.; CASSOLO, A. M. Estudo e aplicação do método aprendizagem baseada em problemas como estratégia educacional no ensino de engenharia de Produção. In: ENCONTRO NACIONAL DE ENGENHARIA DE PRODUÇÃO (ENEGEP), 33., 2013. Anais... Salvador, BA, Brasil, 2013.

THIOLLENT, M. Metodologia da pesquisa-ação. São Paulo: Editora Cortez, 2011.

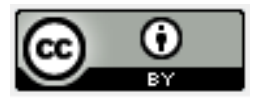

Artigo recebido em 06/12/2014 e aceito para publicação em 22/04/2015

DOI: http://dx.doi.org/ 10.14488/1676-1901.v15i2.1936 